Please send trade news information and illustrations to Arveen Bajaj at the $B D J$, Nature Publishing Group, The Macmillan Building, 4-6 Crinan Street, London N1 9XW. Trade news is provided as a service to readers using text and images from the manufacturer, supplier or distributor and does not imply endorsement by the $B D J$. Normal and prudent research should be exercised before purchase or use of any product mentioned.

\section{Powerful new electric motor}

The new EA-51LT from A-dec offers efficient power, refined control, and seamless integration with the A-dec 500 delivery system. The EA-51LT is an integrated electric motor with endo features. Doctors can now have two electric motors integrated into the delivery system, as well as the ability to switch between high, low, or endo simply by lifting the appropriate handpiece from its holder.

When used with the A-dec 500 deluxe touchpad control, users can switch from standard and restorative procedures to sophisticated endodontic procedures with the touch of a button. The touchpad offers up to 16 memory presets per handpiece position and easy-to-use programmable speed and torque settings.

Operators can utilise the foot control, touchpad, or the ergonomic handpiece itself for precise operation and uninterrupted focus on the work at hand. The EA51LT also offers auto-sensing capabilities with auto-forward, auto-stop, and autoreversing functions, simplifying complex endodontic work.

The new electric motor has a wide array of attachments available for use with burs, reamers, and NiTi files, including a fullydedicated WD-79M endo attachment that offers dentists 90 per cent torque efficiency. In order to meet the exacting precision required for endo procedures, this specialty attachment provides a known torque limit and file speed to match file manufacturers requirements which can significantly reduce the chances of separation. Reader response number 51

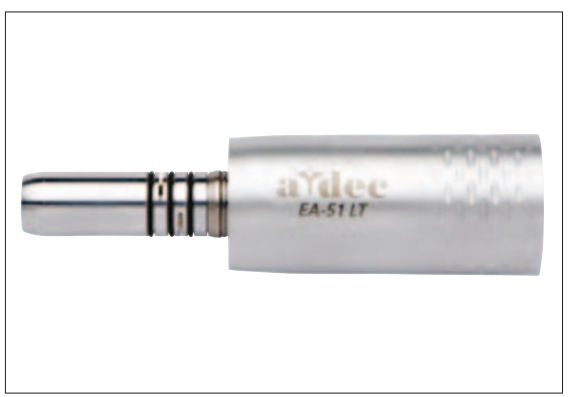

\section{TRADE NEWS \\ WHAT'S NEW}

\section{On-going remineralisation}

Myerson have announced the availability of their new ACP Prophy Paste, Enamel Pro from Premier. ACP (amorphous calcium phosphate) has been proven to stimulate the remineralisation of tooth enamel, helping to prevent tooth decay as well as sensitivity.

When applied to the tooth structure Enamel Pro releases ACP which remains in the tooth tissue even after rinsing. Despite containing the same percentage of fluoride (1.23\%) as conventional pastes, the ACP technology delivers 31\% more fluoride than other prophy pastes as the ACP increases the uptake of fluoride.

Reader response number 50

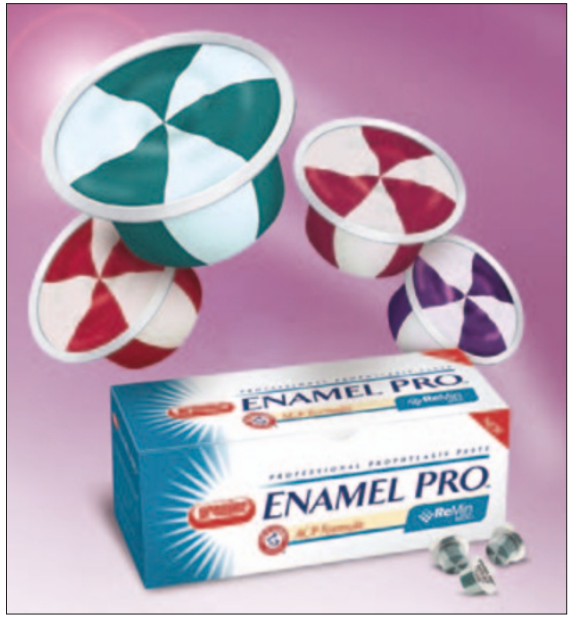

\section{Menu of treatments}

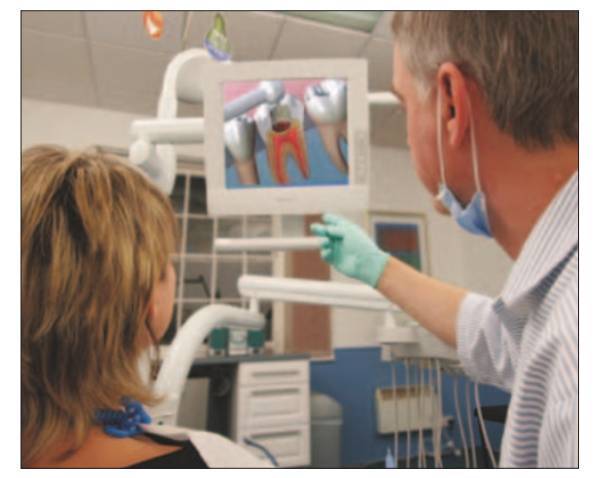

The 'Communicator' is fully integrated into Kodak R4 practice management software. In just a single click 'Communicator' reveals a wide-ranging menu of treatments and procedures, which are viewed by high definition 3D animations created in order to rapidly explain treatments and procedures to patients as well as overcoming the language barriers which are now often a part of modern dentistry.

Over 100 different topics are covered, including many specialist implant and orthodontic sequences.

Reader response number 52

\section{Rapid access to oral health products}

Kent Express supply a wide selection of high quality oral health products, from their own Kent Dental range as well as brand names from leading manufacturers, including Braun, Colgate and Glaxo.

Kent Express is the one stop dental supplier with everything you need in order to meet all of your practice requirements, making purchasing simpler and quicker. Orders can be placed on-line using Kent Connect for extra ease and speed, providing rapid access to the vast range of Kent Express products, news bulletins, special offers and promotions.

Reader response number 53

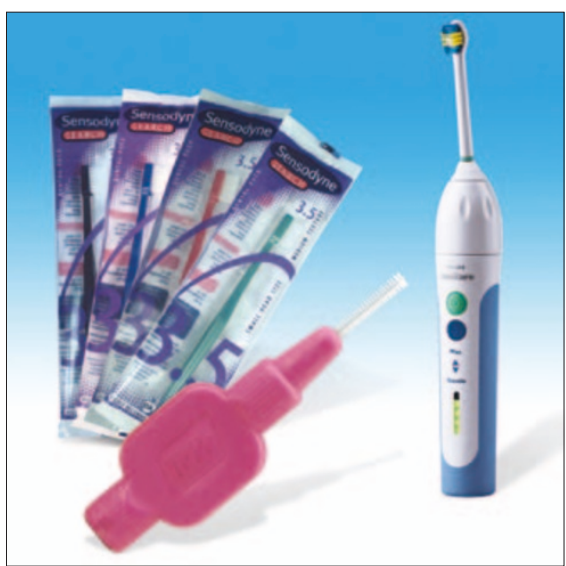



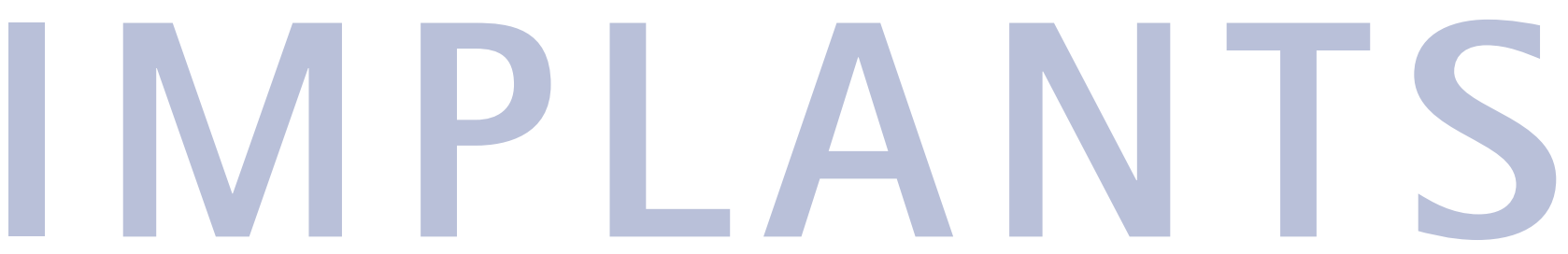

\section{Customised referral pack}

Astra Tech has recently introduced a Referral Pack both to assist its customers and to promote patient referrals. The pack is designed to be a versatile, practical and professional business tool to simplify the referral process and its contents can be readily adapted to complement the specific requirements of individual practices and customised with the practice's name, logo or other discrete details. A CD template in Word and Quark formats is included to enable either in-house or external printing.

Packs are divided into sections which each describe a phase of the referral process. First Contact offers an opportunity to describe the services provided and demonstrate the treatments available to patients of the client practice. Pre-Surgery covers the patient consultation, detailing diagnostics, treatment planning and required materials in preparation for Surgical Phase, which emphasises best practice and illustrates how the patient will be treated throughout the period of referral.

The second section, Restoration Phase, clarifies restorative protocol selection and communications between the laboratory and the dentist, and also identifies the position of the referring dentist during this phase of the treatment.

Reader response number 55

\section{Screw-retained implant}

Cresco from Astra Tech, is a screw-retained implant bridge solution with built-in flexibility and simplicity of application. The system is designed to ensure a passive fit, irrespective of implant system or framework material, and a durable, aesthetic result.

Its simplicity and ease of use allow prosthetic and laboratory procedures to be performed with only a limited number of instruments. Light finger force of approximately $10 \mathrm{Ncm}$ is recommended for seating during try-in, and an increased torque of $35 \mathrm{Ncm}$ for the final setting of the screwretained framework.

Reader response number 54
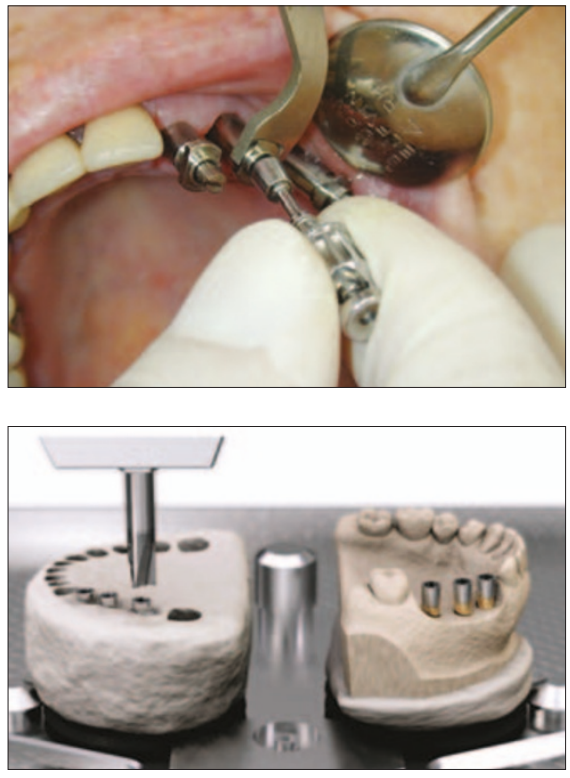

\section{New implant bridge in zirconia}

The new Procera bridge is intended for the same indications and uses the same clinical protocol as the Procera implant bridge titanium for the Brånemark System and NobelReplace. The zirconia bridge offers superlative aesthetics even in cases where the soft tissue recedes - since it is suitable to combine with Nobel Rondo Zirconia and the new Nobel Rondo Gingiva Zirconia porcelain.

Indicated for all positions in the mouth, for fully or partially edentulous patients, the bridge can be up to $30 \mathrm{~mm}$ in diameter and $60 \mathrm{~mm}$ in length.

Reader response number 56

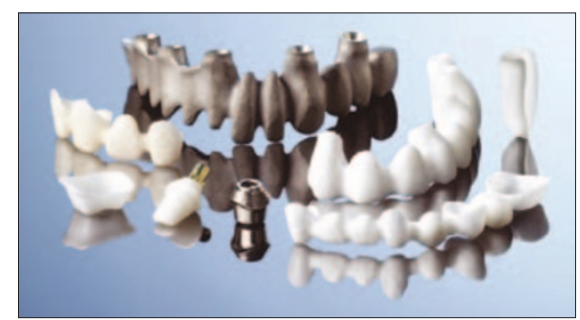

\section{High retention implant cement}

Myerson's Premier Implant Cement is for implant retained prostheses and offers secure retention, yet permits easy removal of the crown. Although designed for implants it can be used for temporaries. The non-eugenol, resin cement features high retention due to a rigid final set and low solubility, providing excellent marginal seal.
Yet, when desired, the restoration can be easily removed due to its unique elasticity. The automix dual-barrel syringe, with disposable mix tips, eliminates hand-mixing and clean-up, ensuring consistent mix and controlled dispensing. As an introductory offer, for a limited period, each kit contains a free Premier Implant Scaler, which can be repeatedly autoclaved and re-sharpened to safely remove excess cement and clean the abutment during prophylaxis. The Premier Implant Cement Kit contains 1 x 5 ml Automix Dual-Barrel Syringe, ten Mix Tips, one Mix Pad and one free Implant Scaler (while stocks last).

Reader response number $\mathbf{5 7}$ 


\section{Implants for edentulous patients}

As patients become increasingly aware of the different treatments available, understanding the benefits of implants as opposed to conventional restorations has become more important. Conventional removable dentures attach to the jaw using suction and so there is little or no stimulation of the bone which can cause deterioration over time. As the bone recedes dentures can become ill-fitting causing patients pain and problems when eating and speaking, resulting in a lack of confidence.

The Straumann Dental Implant System can resolve the problems caused by conventional dentures, providing a stable foundation for replacement teeth and help preserve the neighbouring teeth and bone structure. Attached to an anchorage, Straumann Implant borne dentures can easily be removed for cleaning and replaced with a simple, firm fit.

Reader response number 58

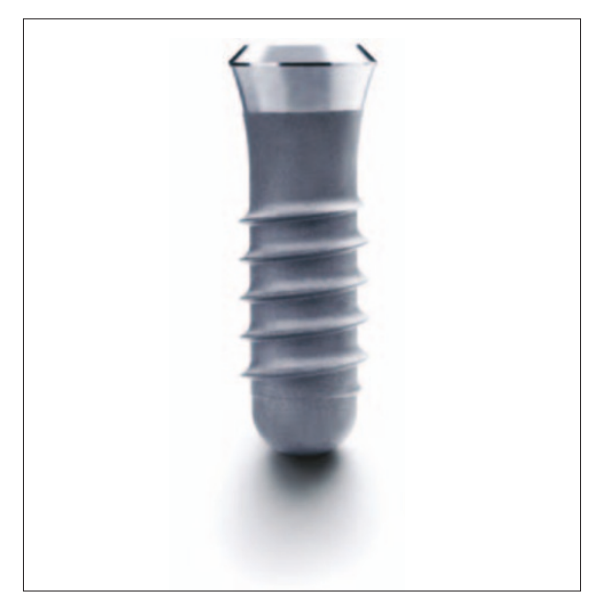

\section{Implant made from biocompatible polymer}

A new line of provisional components, PreFormance Posts and Temporary Cylinders have been developed by $3 \mathrm{i}$ Implant Innovations. These components are made of a strong, biocompatible polymer material called 'Peek' that is easily customised to a patient's tissue contours and anatomic profile.

The PreFormance Post cement-retained provisional option features the Certain QuickSeat Connection, which tells the clinician the abutment is properly seated with an audible and tactile click. It is available in straight or $15^{\circ}$ preangled configurations for ideal angle correction, collar heights in four or six mm to follow gingival contours without trapping cement and Emergence Profile for more natural aesthetics. The PreFormance Post also has a smooth surface for easy provisional restoration reline and a flat side for anti-rotation.

The PreFormance Temporary Cylinder screw-retained option has a knurled surface for mechanical retention of resin material and is available in hexed or nonhexed. The hexed version also offers the Certain QuickSeat Connection.

Reader response number 59

\section{Reduced insertion torque}

Trycare Dental Linkline is the Distributor of Lifecore's new Prima implant system. With a choice between one or two-piece implants, they are available in straight and tapered designs with an internal connection. PrimaSolo, the one-piece tapered implant, has an integrated gold coloured abutment for optimised aesthetics through the gingiva. PrimaConnex are two-piece tapered or straight implants featuring a unique six-lobed internal connection. They support screw-retained, cementretained or overdenture restorations. To help enhance gingival aesthetics the abutments are gold coloured and all the components have an anatomical design.

Both designs feature a $1 \mathrm{~mm}$ smooth gingival collar and Lifecore's tried and tested RBM surface technology, which substantially increases bone-to-implant contact. Their threads are designed for reduced insertion torque to minimise trauma and maintain stability.
Prima implants are designed for immediate placement - which saves time, helps maintain soft and hard tissues, and maximises long-term aesthetic results. Designed for immediate provisionalisation, they eliminate the need for secondstage surgery.

Reader response number 60

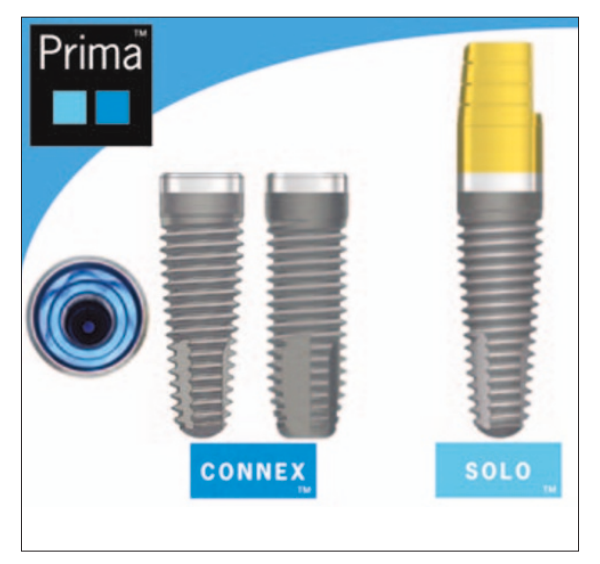

